\title{
A heteromeric protein that binds to a meiotic homologous recombination hot spot: correlation of binding and hot spot activity
}

\author{
Wayne P. Wahls and Gerald R. Smith \\ Fred Hutchinson Cancer Research Center, Seattle, Washington 98104 USA
}

\begin{abstract}
Homologous recombination hot spots are DNA sites that increase the frequency of recombination in their vicinity. The M26 allele of the ade6 gene in Schizosaccharomyces pombe is the first meiotic hot spot with an identified unique nucleotide sequence. We have purified 40,000 -fold a heteromeric protein, containing polypeptides Mts1 $(70 \mathrm{kD})$ and Mts $2(28 \mathrm{kD})$, that binds to the M26 site. Binding in vitro strictly correlates with hot spot activity in vivo for numerous single base pair substitutions in the vicinity of the M26 site, indicating that Mts1/Mts2 activates the M26 site and promotes a rate-limiting step of meiotic recombination. These and other data suggest that homologous recombination may be regulated primarily by discrete DNA sites and proteins that interact with those sites.
\end{abstract}

[Key Words: Genetic recombination; homologous recombination; meiosis; recombination hot spot; recombination proteins; Schizosaccharomyces pombe]

Received April 25, 1994; revised version accepted May 25, 1994.

Homologous recombination, the exchange of genetic information between homologous chromosomes, serves three principal functions. First, recombination generates new combinations of alleles, which may permit evolution to occur more rapidly than would be possible if newly arising mutations maintained their initial linkages. Second, in most organisms recombination is required for the proper segregation of chromosomes at meiosis I (Hawley 1989). Third, recombination is used to repair certain types of DNA damage (Resnick 1976; Szostak et al. 1983).

Although the frequency of recombination between any two genetic markers is roughly proportional to the physical distance between them, some regions of chromosomes, called recombination hot spots, undergo a much higher rate of recombination than others. Mutations or strain differences identifying hot spots were originally found in fungi (Angel et al. 1970; Gutz 1971; MacDonald and Whitehouse 1979) and have been subsequently found in a variety of organisms from bacteriophages (Lam et al. 1974; Stahl et al. 1975) to humans (Wahls et al. 1990a). Known recombination hot spots stimulate recombination up to 30 -fold and exert their effects within a few tens of kilobase pairs. Because recombination hot spots must promote rate-limiting steps of recombination, elucidating how hot spots function will provide a better understanding of how recombination occurs. Presumably, as for transcriptional promoters and enhancers, there are proteins that interact with recombination hot spots to mediate their biological activity.

The $M 26$ recombination hot spot, located in the ade6 gene of the fission yeast Schizosaccharomyces pombe, is a well-characterized eukaryotic recombination hot spot (for review, see Wahls and Smith 1993). Of the almost 400 mutant alleles of ade6 that were isolated by Gutz (1971), the M26 allele is unique; M26 increases the frequency of gene conversion at the ade6 locus to $\sim 10$-fold the level of other ade6 mutations, including the closely linked M375 allele (Fig. 1; Gutz 1971). The M26 and M375 alleles are attributable to single $\mathrm{G} \rightarrow \mathrm{T}$ transversions that create translational stops at codons 46 and 45 , respectively (Fig. 1; Ponticelli et al. 1988; Szankasi et al. 1988). Thus, M375 serves as an excellent negative control for genetic and biochemical studies of recombination promoted by $M 26$. The $M 26$ recombination hot spot functions during meiosis but not during mitosis (Ponticelli et al. 1988; Schuchert and Kohli 1988), exerts its effect in the vicinity of ade6 but not at other loci (Ponticelli et al. 1988), and increases the frequency of both reciprocal exchange and gene conversion events up to 15-fold (Schuchert and Kohli 1988; Grimm et al. 1994). Finally, a heptameric DNA sequence surrounding the M26 mutation (5'-ATGACGT-3'; M26 mutation underlined) is required for hot spot activity (Schuchert et al. 1991). These data suggest that the M26 mutation creates a recognition site for a recombination-promoting protein. 


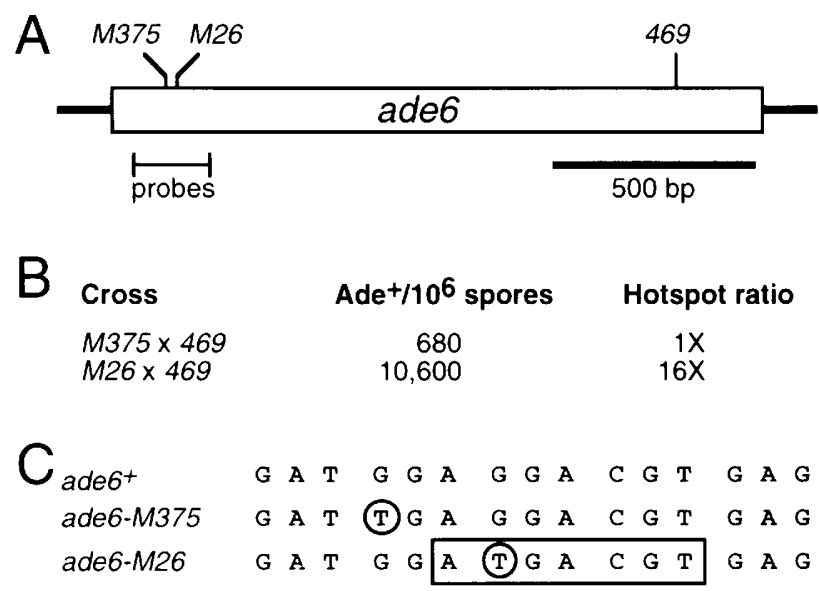

Figure 1. (A) Diagram of the ade6 gene of $S$. pombe showing the positions of the M375, M26, and 469 alleles, and the gel mobility retardation probes used in this study. $(B)$ An example of M26 meiotic homologous recombination hot spot activity (Ponticelli and Smith 1992). (C) Sequence analysis of wild-type, M375, and M26 alleles (Ponticelli et al. 1988; Szankasi et al. 1988). Both alleles are single base pair substitutions (circled) that create translational stops. A specific heptanucleotide sequence (boxed) surrounding the M26 mutation is required for hot spot activity in vivo (Schuchert et al. 1991).

\section{Results}

\section{Detection of an M26-binding protein}

Because the M26 recombination hot spot functions only during meiosis (Ponticelli et al. 1988; Schuchert and Kohli 1988), we reasoned that a putative M26 DNA-binding protein might be meiotically induced. Therefore, we initially searched for M26-binding activity in extracts of cells undergoing meiosis.

Induction of meiosis in $S$. pombe strain GP535 $\left(h^{-}\right.$ pat $1-114^{\text {ts }}$ end $1-458$ ade6-M26) was achieved by temperature shift as described previously (Szankasi and Smith 1992). Three different assays were used to judge the efficiency and synchrony of the induced meiosis (Szankasi and Smith 1992). First, the bulk of premeiotic DNA synthesis occurred between 2 and $3 \mathrm{hr}$ of meiosis (Fig. 2). Second, the majority of cells completed the second meiotic division between 5 and $6 \mathrm{hr}$ after induction (Fig. 2). Third, we observed appropriate meiotic induction of exonuclease I (Exo I) (Fig. 2), a double-stranded DNA (dsDNA) exonuclease that is meiotically induced (Szankasi and Smith 1992). In a related study two meiotic recombination genes, rec7 and rec8, were induced at 2 and $3 \mathrm{hr}$ of meiosis (Fig. 2; Lin et al. 1992). We conclude that the meiotic induction was synchronous and that meiotic enzymes were induced appropriately.

We used a gel mobility retardation assay to determine whether extracts of $S$. pombe cultures at various time points of meiosis contained a protein that binds to the M26 recombination hot spot. Probes (Fig. 1) were derived from ade6 DNA bearing either the single base pair M26 substitution (recombination hot spot) or the single base pair M375 substitution (normal recombination levels). As shown in Figure 2B, two M26-specific binding activities (complex 1 and complex 2) were detected in extracts of mitotic and meiotic cells. Because the M375 allele maps very close to M26 (Fig. 1) and exhibits normal recombination levels in genetic crosses, it serves as an excellent control to correlate these biochemical analyses with genetic hot spot activity. Probes from wild-type ade6 DNA also failed to be bound by protein (data not shown; see also Fig. 7, below), indicating that the M26 mutation generated a protein-binding site (and disproving the possibility that the M375 mutation disrupted a pre-existing site in wild-type DNA). The presence of M26 DNA-binding activity was independent of whether or not the cells harbored the M26 allele at ade6 (data not shown) and could be competed away quantitatively with unlabeled $M 26$ probe but not with unlabeled $M 375$ probe (data not shown). These data indicate that M26 recombination hot spot-binding proteins were present and constitutively expressed in mitotic and meiotic cells. The meiotic specificity of the M26 hot spot in genetic crosses
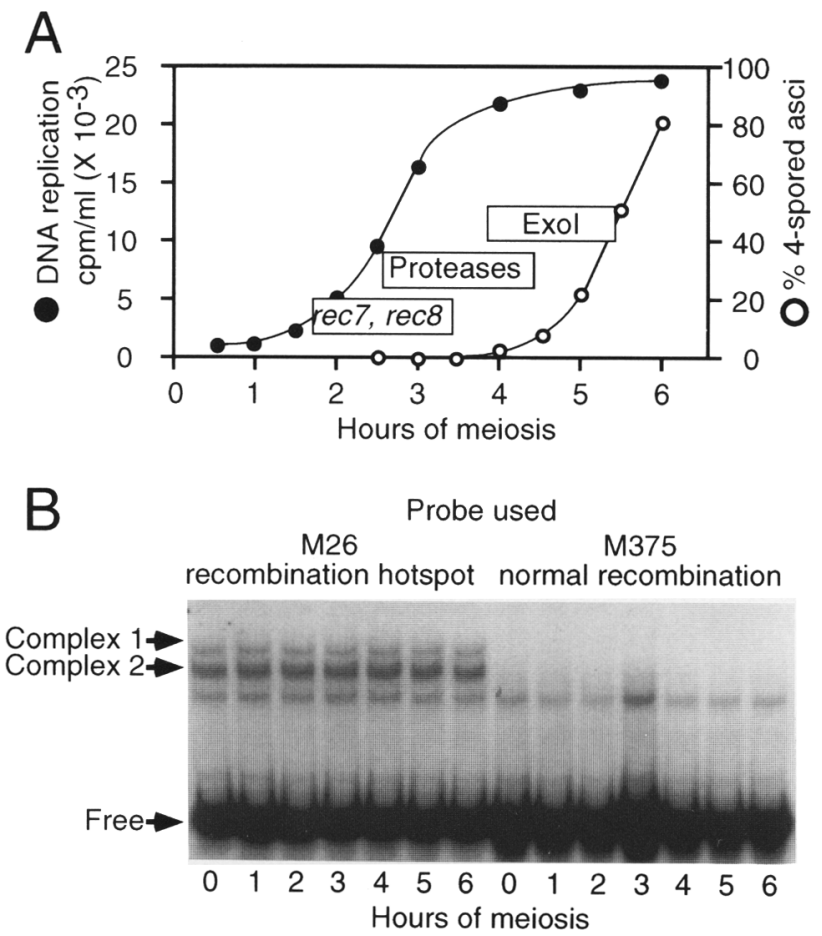

Figure 2. Detection of M26-specific DNA-binding proteins. $(A)$ Time course of synchronous meiosis in $S$. pombe. Boxes indicate times at which the indicated activity is induced. The rec7 and rec8 transcript induction data are from Lin et al. (1992). (B) Gel mobility retardation assay. Extracts were prepared as described (Szankasi and Smith 1992) from mitotic cells (hour 0) and meiotic cells (hours $1-6$ after shift of the culture to $34^{\circ} \mathrm{C}$ ). Binding reactions were in $15 \mu \mathrm{l}$ and contained $10 \mu \mathrm{g}$ of protein, $1 \mu \mathrm{g}$ of poly[d(I-C)], and 4 fmoles of the 215 -bp probe containing either M26 or $M 375$ single base pair substitutions. The position of two M26-specific complexes (1 and 2) are indicated; (Free) The position of unbound DNA. 
must therefore result from another factor (see Discussion).

\section{Binding occurs at M26}

A specific heptamer, 5'-ATGACGT-3', is required for M26 hot spot activity in vivo (Schuchert et al. 1991). We used methylation interference to determine the DNA sequence in our M26 probe that was bound by protein. Methylation of any G residue within the $M 26$ heptamer abolished protein binding, whereas probes methylated outside the heptamer were bound efficiently by protein (Fig. 3). Thus, the methylation interference footprint superimposes on the DNA sequence required for hot spot activity and shows that the protein binds directly to the M26 site.

\section{Low abundance of M26 DNA-binding protein}

To estimate the abundance of the M26-specific DNAbinding proteins in each cell, we determined the amount of probe that was bound by serial dilutions of unfraction-

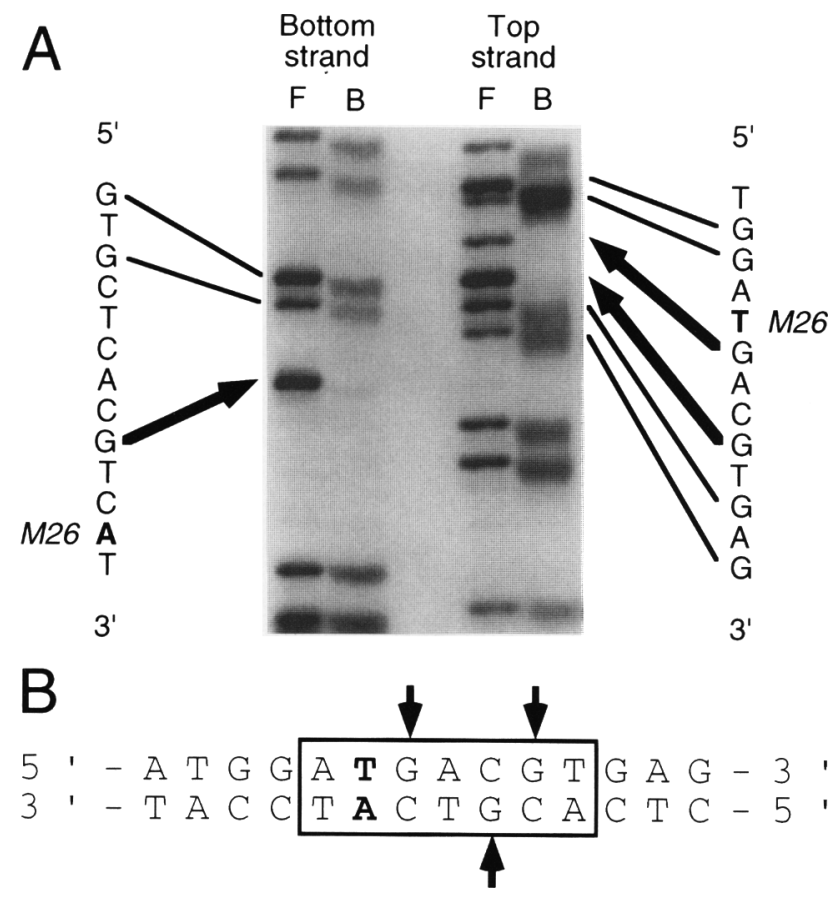

Figure 3. Protein-DNA binding occurs at the M26 site. $(A)$ Methylation interference assays of both strands of the M26 probe. (Bottom, Top) Strand that was 3'-end labeled; (F) free probe; $(\mathrm{B})$ bound probe. Arrows indicate positions of guanine bases which, when N7-methylated, interfere with proteinDNA binding. $(B)$ Summary of methylation interference data. The M26 mutation is in boldface type; the heptanucleotide sequence required for hot spot activity in vivo is boxed (Schuchert et al. 1991); arrows indicate position of close protein contacts with guanine bases in the major groove. Note that methylation of guanines immediately flanking the heptamer does not interfere with protein-DNA binding. ated cell extract. Under conditions with DNA concentration above $K_{\mathrm{d}}\left(\sim 1 \times 10^{-9} \mathrm{M}\right)$ and probe excess, the extract from $\sim 1.2 \times 10^{6}$ cells (12 $\mu \mathrm{g}$ of fraction I protein) was required to shift the mobility of 0.4 fmole of the probe (data not shown). These data suggest that there are 200 M26-binding proteins per cell. Estimates based on the recovery of purified protein (Table 1) give a similar value.

\section{Purification of M26 DNA-binding activity}

We used standard chromatographic techniques including a final M26 DNA affinity column (Fig. 4A) to purify the M26-specific DNA binding activity from extracts of mitotic cells of strain GP61 (h- leu1-32 end1-458). As with the meiotic extracts (Fig. 2B), fractions from all stages of purification generated two M26-specific protein-DNA complexes when analyzed on gel mobility retardation gels (Fig. 4C). We calculate that we achieved $\sim 40,000$ fold purification of the M26 DNA-binding activity (Table 1). As shown in Figure 4B, SDS-PAGE analysis revealed that purified fraction VI was composed primarily $1 \geqslant 50 \%$ by weight) of two polypeptides. We call these polypeptides M-twenty-six-binding proteins, abbreviated as Mts $1(\overline{70} \mathrm{kD})$ and $M t s 2(28 \mathrm{kD})$, respectively.

Although the factors that produced the two different protein-DNA complexes cofractionated throughout the purification (Fig. 4C), they also showed some degree of independence. Analysis of sequential fractions from the final column revealed that factors required for complex 1 eluted from the column slightly earlier than factors required for complex 2 (Fig. 5B). Similar behavior was observed with sequential fractions from other columns (data not shown). In each case, the factors responsible for the two complexes always eluted with some overlap (suggesting that they shared common subunits), and they were often, but not always, offset slightly from one another (suggesting that they were distinct).

SDS-PAGE analysis of fractions from the final column revealed that the Mtsl and Mts2 polypeptides cofractionated with each other (Fig. 5A) and with the entire region of M26-specific DNA-binding activity (i.e., both complex 1 and complex 2, Fig. 5B). (The slightly earlier appearance of Mts1 relative to Mts2 in Fig. 5A may be attributable to a nominal gel-filtration effect as the proteins elute at high salt from the M26 DNA affinity column.) These data suggest that Mts1 and Mts2 exist as a heterodimer and, furthermore, that the Mts1/Mts2 heterodimer plays a role in the formation of both complexes.

\section{Mts1 and Mts2 exist and bind as a heteromeric complex}

To investigate whether Mts1 and Mts2 existed as a heterodimer in solution, we treated purified fraction VI with glutaraldehyde, which cross-links closely associated primary amines, and analyzed the products on an SDSpolyacrylamide gel (Fig. 6A). We observed a coordinate reduction in Mts1 and Mts2 band intensities and the 
Table 1. Purification of M26 DNA-binding activity

\begin{tabular}{|c|c|c|c|c|c|c|c|}
\hline Fraction & Source & $\begin{array}{l}\text { Total protein } \\
\text { (mg) }\end{array}$ & $\begin{array}{l}\text { Total activity } \\
\text { (units) }^{\mathrm{a}}\end{array}$ & $\begin{array}{c}\text { Specific activity } \\
(\mathrm{U} / \mathrm{mg})\end{array}$ & $\begin{array}{l}\text { Yield per } \\
\text { step }(\%)\end{array}$ & $\begin{array}{l}\text { Yield total } \\
\qquad \% \mid\end{array}$ & $\begin{array}{c}\text { Purification } \\
\text { (fold) }\end{array}$ \\
\hline I & cell extract & 12,700 & 230,000 & 18 & 100 & 100 & 1.0 \\
\hline II & $0-41 \%\left(\mathrm{NH}_{4}\right)_{2} \mathrm{SO}_{4} \mathrm{ppt}$ & 4,800 & 210,000 & 44 & 91 & 91 & 2.4 \\
\hline III & SP-Sepharose & 226 & 150,000 & 660 & 71 & 65 & 37 \\
\hline IV & ssDNA-cellulose & 32.9 & 30,000 & 910 & 20 & 13 & 51 \\
\hline $\mathrm{V}$ & Mono-S & 9.75 & 21,000 & 2,200 & 70 & 9 & 120 \\
\hline VI & $\mathrm{M}_{26_{18}}$ DNA-Sepharose & 0.01 & 6,900 & 690,000 & 33 & 3 & 38,000 \\
\hline
\end{tabular}

${ }^{a}$ One unit is the amount of protein required to shift $50 \%$ of the M26 probe (4 fmoles) in standard gel mobility retardation assays.

appearance of a novel band of $98 \mathrm{kD}$ (the expected sum of Mts1 and Mts2 molecular masses); higher order aggregates were not observed. These data suggest that Mts1 and Mts2 exist as a heterodimer in solution.

To characterize the protein-DNA complexes, we eluted the Mts1 and Mts2 polypeptides individually
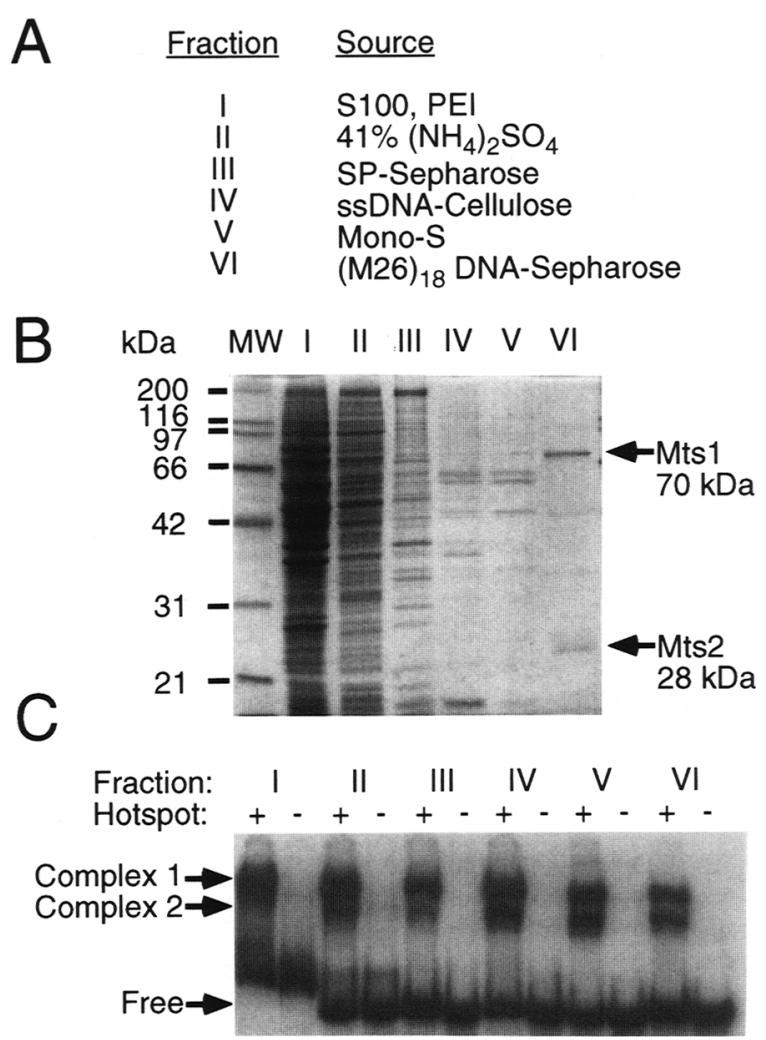

Figure 4. Purification of M26-specific DNA-binding proteins. (A) Summary of purification procedure. (B) Coomassie-stained, $12 \%$ SDS-PAGE analysis of fractions from purification. (MW) Molecular weight standards, $3 \mu \mathrm{g}$; (fraction I) $25 \mu \mathrm{g}$ (fraction II);

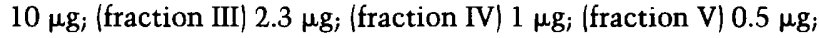
(fraction VI) $0.5 \mu \mathrm{g}$. (C) Gel mobility retardation assay of fractions from purification. Assay and probes were as in Fig. 2 and contained $30 \mu \mathrm{g}$ (fraction I); $11 \mu \mathrm{g}$ (fraction II); $1 \mu \mathrm{g}$ (fraction III); $0.5 \mu \mathrm{g}$ (fraction IV); $0.2 \mu \mathrm{g}$ (fraction V); $<0.001 \mu \mathrm{g}$ (fraction VI). $(+)$ M26 probe (recombination hot spot); $(-)$ M375 probe (normal recombination levels). from an SDS-polyacrylamide gel into a denaturing solution; then we renatured the proteins and used mixing experiments to determine the requirements for M26-specific DNA binding (Fig. 6B). As a control, we conducted the same experiments with fraction VI that had not been subject to SDS-PAGE. When fraction VI was denatured and renatured, both protein-DNA complexes were reformed. Under identical assay conditions, no binding was detectable with Mts1 alone or with Mts2 alone. However, when isolated Mts1 and Mts2 were either renatured and mixed together, or mixed together and renatured, M26-specific complex 1 was restored. These results show that a heterodimer or heteromultimer of Mts1 and Mts2 is necessary and sufficient for formation of protein-DNA complex 1 . From protein titration in gel mobility retardation assays, we calculate that at least $50 \%$ of the purified Mts1/Mts2 heterodimer molecules in fraction VI were active for M26 binding (data not shown).

On much longer exposures of the X-ray film, additional M26-specific protein-DNA complexes were observed in reactions with Mts1 alone (complex 3) and Mts2 alone (complex 4; Fig. 6B). Complex 3 migrated
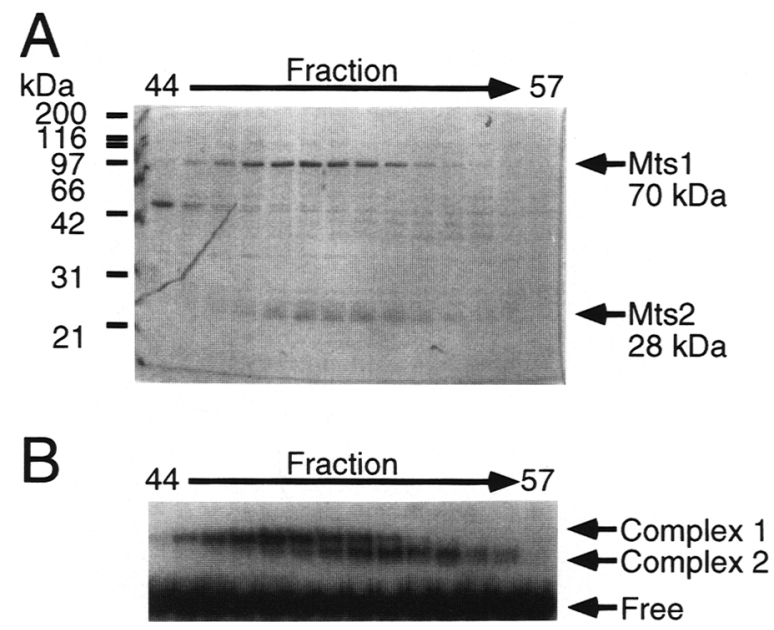

Figure 5. Coelution of Mts1 and Mts2 polypeptides with M26 DNA-binding activity in fractions from final column. Sequential column fractions were analyzed on Coomassie-stained, $12 \%$ SDS-polyacrylamide gel $(A)$ and by gel mobility retardation assay for binding to $M 26$ probe $(B)$. 

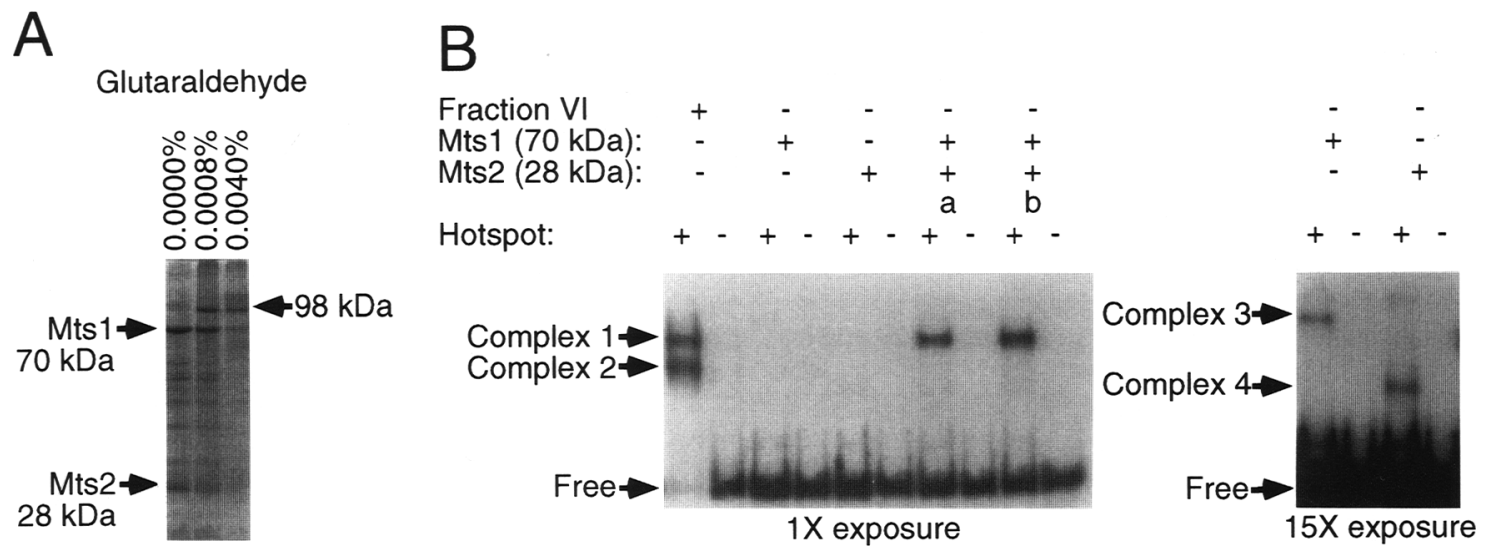

Figure 6. Evidence for heterodimer. (A) Glutaraldehyde cross-linking of Mtsl and Mts2. Cross-linking of purified fraction VI was for $10 \mathrm{~min}$ at $37^{\circ} \mathrm{C}$ under the indicated conditions. The samples were then fractionated on a Coomassie-stained, $12 \%$ SDS-polyacrylamide gel. (B) Reconstitution of M26-specific band shift using purified components. Fraction VI, gel-purified Mtsl, and gel-purified Mts2 were individually denatured, renatured, mixed as indicated, and tested for M26 DNA-binding activity. (Complex 1) Heterodimer of Mts1 and Mts2; (complex 2) heterotrimer of Mts1, Mts2, and third factor?; (complex 3) homodimer of Mts1-low affinity binding; (complex 4) homodimer of Mts2-low affinity binding. (a) Renatured and mixed; (b) mixed and renatured. Gel mobility retardation assay conditions and probes were as in Fig. 2.

more slowly than complex 1 (Mts1/Mts2 heterodimer bound to $M 26$ probe), suggesting that it was composed of a homodimer of Mtsl bound to the M26 probe. Likewise, the position of complex 4 suggested that it consisted of a homodimer of Mts2 bound to the probe. (These presumed multimeric states have not been directly demonstrated.) Thus, while Mts1 and Mts2 exist as a heterodimer (or heteromultimer) in solution (Fig. 6A) and a heterodimer of Mts1 and Mts2 is required for optimal binding to the $M 26$ site (Fig. 6B), the individual Mtsl and Mts2 polypeptides are capable of some, albeit lower affinity, M26-specific DNA binding.

In similar experiments, we tested the ability of the purified proteins to bind to single-stranded M26 probes. No single-stranded DNA (ssDNA) binding was observed (data not shown), suggesting that the Mts1/Mts2 heterodimer binds exclusively to dsDNA containing the M26 site.

\section{Evidence for a third factor}

Although fraction VI could be denatured and renatured to reconstitute both complex 1 and complex 2 , the identical experiment using purified Mtsl and Mts2 reconstituted only complex 1 (Fig. 6B). Thus, there must have been some third factor (Mts3), not cofractionating with $70-$ and $28-\mathrm{kD}$ polypeptides, that contributed to formation of complex 2 ; that factor was fractionated away when Mts1 and Mts2 were gel purified. Glutaraldehyde cross-linking indicated that Mts1 and Mts2 exist as a heterodimer in solution (Fig. 6A). Furthermore, in fractions from columns, Mts1 and Mts2 coeluted with each other and with both of the M26-specific DNA-binding activities (complex 1 and complex 2; Fig. 5), suggesting that the Mts1/Mts2 heterodimer is required for both complexes. On the basis of those data, we assume that
Mts3 interacts with the Mts1/Mts2 heterodimer to give rise to protein-DNA complex 2 .

Polypeptides of $\sim 40 \mathrm{kD}$ seemed to coelute with protein-DNA complex 2 and are possible candidates for the third factor Mts3 (Fig. 5). If so, SDS-PAGE analyses suggest that Mts3 must either stain poorly or be a low-abundance protein that increases the affinity of the Mts1/ Mts2 heterodimer for the M26 site. However, the 40-kD polypeptides are not present in equimolar concentrations with Mts1 and Mts2 (Fig. 5), they do not efficiently cross-link to the Mts1/Mts2 heterodimer when treated with glutaraldehyde (Fig. 6), and they are apparently absent from some purifications (data not shown), suggesting that the $40-\mathrm{kD}$ polypeptides are unlikely candidates for Mts3. Because there are no other obvious polypeptide candidates for Mts3, it may not be composed of protein. Mts3 could be a small molecule, metal ion, or other cofactor that changes the conformation (and electrophoretic mobility) of the protein-DNA complex. Alternatively, as has been found for some other proteins involved in macromolecular nucleic acid metabolism (Kole and Altman 1981; Greider and Blackburn 1987; Young et al. 1991), Mts3 might be composed of RNA. RNA has been found in the 40,000-fold purified fraction VI, but the available evidence suggests that it is not a functional subunit of the Mts1/Mts2 protein-DNA binding activity (Wahls 1994). Further investigation may reveal the nature of Mts3 and its role in binding of the Mtsl/Mts2 heterodimer to the $M 26$ recombination hot spot.

\section{Mts1/Mts2 binding at M26 correlates with hot spot activity}

Because Mts1/Mts2 bound only probes bearing the M26 recombination hot spot (Figs. 2, 4, and 6) and footprinted to the heptameric sequence required for hot spot activity 
(Fig. 3), it was likely that Mts1/Mts2 protein binding was required for hot spot activity. To confirm this, we tested the ability of purified fraction VI to bind to DNA molecules that contained single base pair substitutions in the vicinity of the M26 site. As shown in Figure 7, substitutions within the M26 heptamer abolished both protein binding in vitro and hot spot activity in vivo, although substitutions outside the M26 heptamer abolished neither protein binding nor hot spot activity. Furthermore, one substitution that decreased hot spot activity $\sim 40 \%$
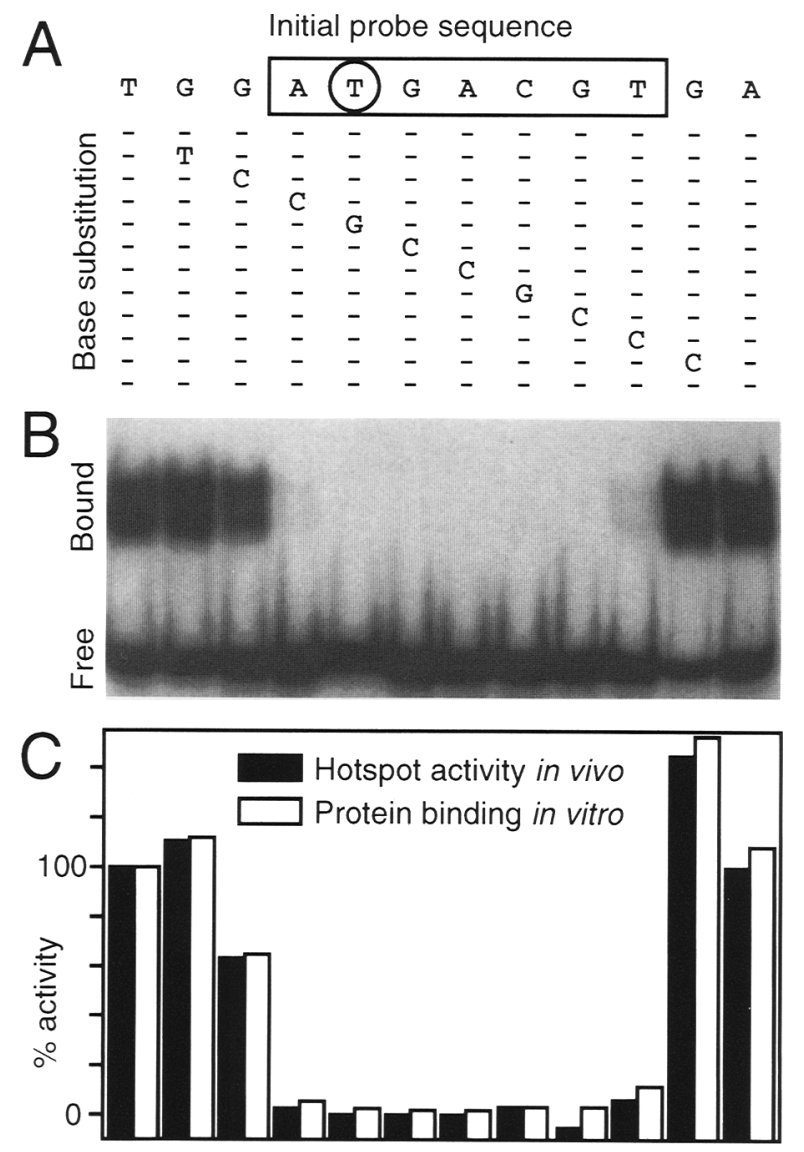

Figure 7. Hot spot activity in vivo correlates with Mts1/Mts2 protein binding in vitro. $(A)$ DNA sequences of probes used. (Circle) M26 mutation; (box) heptameric sequence required for hot spot activity in vivo (Schuchert et al. 1991). The 215-bp probes differed only by the indicated single base pair substitutions. (B) Gel mobility retardation assay using purified Mtsl/ Mts2 heterodimer (fraction VI) and the probes indicated in $A$. (C) Correlation of hot spot activity in vivo (Schuchert et al. 1991) with Mts1/Mts2 protein binding in vitro for single base pair substitutions in the vicinity of the M26 site. For the in vivo data, the values are normalized so that $100 \%$ equals the $M 26$ (hot spot) recombinant frequency and 0\% equals the $M 375$ (normal) recombinant frequency. For quantitation of the in vitro data, the gel in $B$ was analyzed using a Molecular Dynamics model 400A PhosphorImager and ImageQuant version 3.2 (Molecular Dynamics) software. The relative amount of each probe bound was normalized to the relative amount of binding of the unsubstituted M26 probe in lane 1. also decreased protein binding $\sim 40 \%$, whereas another substitution that increased hot spot activity $40 \%$ also increased protein binding a similar amount. Thus, the amount of recombination hot spot activity observed in vivo (Schuchert et al. 1991) correlated precisely with the amount of protein-DNA binding in vitro for every single base pair substitution. Identical results were obtained with protein fraction II from all time points of meiosis (data not shown). From this strict correlation of in vivo genetic hot spot activity and in vitro Mts1/Mts2 protein binding, we conclude that binding of Mts1/Mts2 protein to the heptanucleotide M26 DNA sequence is required for the recombination hot spot activity.

\section{Discussion}

\section{Recombination hot spots, sequences, and factors}

Recombination hot spots have been studied extensively, particularly in Saccharomyces cerevisiae, to gain insight into individual steps of recombination pathways. For example, double-strand breaks appear during meiosis in regions that have high recombination frequencies (Sun et al. 1989; Cao et al. 1990; Sun et al. 1991; Wu and Lichten 1994), supporting models in which double-strand breaks initiate recombination (Resnick 1976; Szostak et al. 1983). Furthermore, certain mutations that reduce meiotic recombination also block or change double-strand break formation (Cao et al. 1990; Alani et al. 1990; Sun et al. 1991; Bishop et al. 1992), again supporting a role for double-strand breaks in recombination. However, specific DNA sequences (and interacting factors) responsible for the formation of double-strand breaks and the initiation of recombination have not, to our knowledge, been identified in $S$. cerevisiae.

In contrast, a specific nucleotide sequence required for the M26 hot spot activity of $S$. pombe has been identified: 5'-ATGACGT-3' (M26 mutation underlined) confers full hot spot activity, whereas alleles lacking this precise sequence (such as $M 375$ ) also lack hot spot activity (Schuchert et al. 1991). The availability of alleles such as $M 26$ that function as a hot spot, and alleles such as M375 that exhibit normal recombination levels, allowed us to use a gel mobility retardation assay to identify M26-specific binding proteins and to monitor the purification of those proteins.

\section{Function of M26 site and binding proteins}

Because binding of the Mts1/Mts2 heterodimer strictly correlates with hotspot activity, it seems likely that its role is to promote an early, rate-limiting step in the initiation of recombination. Three possible modes of action seem plausible. First, the protein may act catalytically at the M26 site to generate recombinogenic lesions such as nicks or double-strand breaks. Second, the bound protein could act as a signal to recruit recombination enzymes in much the same way that transcription factors serve to target RNA polymerase complexes to promoters. Third, binding of Mtsl/Mts2 to the M26 site could result in an 
"open" chromatin structure, or some other localized perturbation of DNA structure, which could be more accessible to the meiotic recombination machinery. The last mechanism has been proposed recently for $S$. cerevisiae; there is a correlation between nuclease-sensitive sites in chromatin and sites that are "hot" for meiotic recombination (Wu and Lichten 1994). Furthermore, binding of any of three different transcription factors, which could alter local chromatin structure, has about a twofold effect upon recombinant frequencies at the HIS4 locus (White et al. 1991, 1993).

Several results suggest that other factors interact with the Mts1/Mts2 protein, perhaps as a multicomponent complex, to mediate hot spot activity. First, whereas Mts1 and Mts2 copurify as a heterodimer in solution (Fig. 6), and a heterodimer (or heteromultimer) is required for optimal binding to the M26 site (Fig. 6), the individual subunits are capable of some binding (Fig. 6). This is reminiscent of heterodimeric transcription factors (Blackwood et al. 1992) and provides a possible level of control: Other as-yet-unidentified dimerization partners may contribute to the regulation of hot spot activity. Second, evidence suggests that a third factor (Mts3) is associated with the heterodimer (see Results; Fig. 6). Third, although the M26 hot spot functions only during meiosis (Ponticelli et al. 1988; Schuchert and Kohli 1988), the M26 DNA-binding proteins are present in extracts from both mitotic and meiotic cells (Fig. 2). Some other factor must confer the meiotic specificity. This factor might be encoded by one of the 16 known meiotic rec genes of $S$. pombe (Ponticelli and Smith 1989; DeVeaux et al. 1992), at least some of which are strongly induced during meiosis (Lin et al. 1992; Lin and Smith 1994).

The presence of Mts1/Mts2 in mitotic cells has two implications. First, the protein may have an as-yet-unidentified role in mitotic cellular metabolism in addition to its role in activating the meiotic recombination hot spot. Second, binding of Mts1/Mts2 to the M26 site is necessary but not sufficient to activate the meiotic recombination hot spot. Other steps are obviously required in the pathway from substrates to recombinant products. Thus, although binding of Mts1/Mts2 to the M26 site stimulates a rate-limiting step in the induction of meiotic recombination, failure of the hot spot to function in mitotic cells could be easily explained by a different step in the pathway being rate-limiting in mitotic cells.

When $3 \mathrm{kbp}$ of ade6 DNA containing the M26 site was moved to the ura4 locus, the hot spot failed to function, suggesting that either a second cis-linked site or a particular chromatin structure at ade6 was required for hot spot activity (Ponticelli and Smith 1992). Other experiments, however, show that the M26 site can function as a hot spot when it is moved or when the local chromosomal structure surrounding ade6 is perturbed: The $M 26$ heptamer has hot spot activity when it is moved 60 or $750 \mathrm{bp}$ downstream of its normal location at ade6 (J). Metzger and J. Virgin, pers. comm.); in some constructs, M26 does function as a hot spot when moved to ura4 (J. Virgin, pers. comm.); and the hot spot functions when the chromosomal structure surrounding ade6 is altered by inserting a duplication (Schuchert and Kohli 1988). Thus, other naturally occurring M26 sites in the $S$. pombe genome may also function as recombination hot spots.

To estimate the abundance of naturally occurring M26 sites in the $S$. pombe genome, we determined the number of M26 heptamers in S. pombe DNA of known sequence. If nucleotides were randomly associated, one would expect to find $\sim 71$ copies of any particular heptamer in the two strands of the $583 \mathrm{kbp}$ of $S$. pombe DNA that has been sequenced (GenBank v. 77 and EMBL v. 35). Our homology search detected the M26 heptamer only 13 times, whereas 10 randomized M26 heptamers were found an average of 69 times each (range of 44-101, $\sigma_{n}=18$ ). We conclude that the M26 heptamer is about sixfold under-represented in the $S$. pombe genome. This suggests that there are $\sim 300$ heptameric $M 26$ sites in the 14-Mbp (Fan et al. 1989) S. pombe genome.

These observations allow a speculative calculation of the fraction of meiotic recombination attributable to M26; 300 M26 sites per genome might be sufficient to account for the observed rates of meiotic recombination. The $S$. pombe genome contains $\sim 14 \mathrm{Mbp}$ (Fan et al. 1989 ) with a meiotic map size of $\sim 2000 \mathrm{cM}$ (Munz et al. 1989); 40 reciprocal exchange events occur per meiosis. If the calculated 300 genomic M26 heptamers are all active as hot spots and each promote recombination in 5\% of meioses [the level of conversion at ade6-M26 /Gutz $1971)$ ], then $\sim 15$ conversion events per meiosis would be attributable to M26 sites. About $65 \%$ of the apparent conversion events of $M 26$ are accompanied by reciprocal exchange (Grimm et al. 1994). Thus, $\sim 10$ reciprocal exchange events per meiosis would be attributable to M26 sites. That is, the predicted 300 M26 sites in the $S$. pombe genome $10.015 \%$ of genomic DNA) could concievably be responsible for up to $25 \%$ of all meiotic homologous recombination events.

\section{Recombination hot spots as regulatory elements}

Recombination hot spots are active throughout the genomes of organisms from bacteriophages (Lam et al. 1974; Stahl et al. 1975) to humans (Wahls et al. 1990a). Some hot spots (such as M26) function only during meiosis (Ponticelli et al. 1988; Schuchert and Kohli 1988), some function only during mitosis (Keil and Roeder 1984; Voelkel-Meiman et al. 1987), and some function during both meiosis and mitosis (Treco and Arnheim 1986; Wahls et al. 1990b). Thus, in addition to altering the spatial distribution of recombination events (i.e., promoting recombination within a few tens of kilobase pairs of their locations), recombination hot spots differentially influence the amount of recombination occurring during mitosis and meiosis.

These observations imply that a significant fraction of recombination may be regulated by a finite number of discrete sites such as M26. In this scenario, the amount of recombination that occurs in any physical interval depends more on the relative proximity (or local density) 
of active recombination hot spots than on its size. Larger physical intervals would generally, but not always, contain a greater number of active hot spots and would thus have a correspondingly greater genetic size. One class of hot spots might be active during mitosis to provide a certain basal level of recombination. Other initiators of recombination, such as DNA damage, clearly contribute to that basal level. During meiosis, when recombination rates must be highly induced to ensure appropriate chromosomal disjunction and to generate genetic diversity, meiotic hot spots would be activated. Thus, discrete sites and their binding proteins could account for the observed regulation of recombination both along the chromosome and during the life cycle.

The proposal that most recombination may be regulated by a finite number of discrete sites is likely to remain speculative for some time. It is clear, however, that recombination hot spots and their associated proteins promote rate-limiting steps of homologous recombination. By understanding how hot spots function, we expect to elucidate discrete steps in pathways of homologous recombination.

\section{Materials and methods}

\section{DNA}

Gel mobility retardation substrates were gel purified, 215-bp fragments of ade6 DNA isolated from plasmid or M13 replicative form DNA after digestion with StyI. The M26 site is centrally located in these fragments. M13 clones harboring single base pair substitutions in the vicinity of the M26 site were described (Schuchert et al. 1991). DNA fragments for methylation interference were isolated from pUCD4 (354-bp HaeIII fragment of ade6 cloned into the HincII site of pUC19; A.S. Ponticelli and G.R. Smith, unpub.) by digestion with $\mathrm{XbaI}$ and StyI. Probes were labeled with $\left[\alpha^{-32}\right.$ P $]$ dNTPs using the Klenow fragment of DNA polymerase I. Standard techniques were used for all DNA manipulations (Sambrook et al. 1989).

\section{Gel mobility retardation assays}

The gel mobility retardation assays were as described previously (Wahls et al. 1991). The 15- $\mu$ l binding reactions contained $10 \mu \mathrm{g}$ of protein, $1 \mu \mathrm{g}$ of poly[d(I-C)], and 4 fmoles of 215-bp StyI-StyI fragment of ade6 DNA.

\section{Methylation interference assay}

The assay was as described (Baldwin 1988) using protein fraction II.

\section{Cell culture and meiotic induction}

Meiotic and mitotic extracts were prepared from $S$. pombe strains GP535 ( $h^{-}$ade6-M26 pat1-114 end1-458) and GP61 $\left(h^{-}\right.$ leu1-32 end1-458), respectively. Strain genealogies are available upon request. Media, culture techniques, and induction of meiosis by thermal inactivation of the pat $1-114^{\text {ts }}$ repressor of meiosis have been described (Szankasi and Smith 1992; Wahls et al. 1993). Preparation of extracts from meiotic cultures and analysis of the meiotic time course, DNA replication, and Exo I enzymatic activity were as described (Szankasi and Smith 1992). Induction of meiotic proteases was inferred from the increased mobility of protein-DNA complexes on mobility retardation gels when extracts were made without adequate protease inhibitors (data not shown). For large-scale purification GP61 cells were grown mitotically in yeast extract liquid at $32^{\circ} \mathrm{C}$ to late $\log$ phase $\left(A_{595}=3.5, \sim 3.5 \times 10^{7}\right.$ cells $\left./ \mathrm{ml}\right)$ in a 30 -liter capacity fermentor (New Brunswick). The cells were harvested, resuspended in 0.25 volume (vol/wt) of disruption buffer containing $4 \times$ inhibitors (see below), frozen by drizzling into liquid $\mathrm{N}_{2}$, and stored at $-70^{\circ} \mathrm{C}$ in sealed containers until they were processed further.

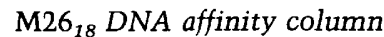

Two complementary, overlapping 31-nucleotide oligonucleotides (M26-1，5'-TTGGAAATTGATGGATGACGTGAGCACATTG-3' and M26-2, 5'-CCAACAATGTGCTCACGTCATCCATCAATTT-3', M26 mutation is underlined) were annealed to generate a duplex M26 fragment, with 4-bp cohesive ends, which can only ligate in head-to-tail multimers. Tandem arrays were generated and processed as described previously to construct an M26 DNA-Sepharose CL2B column (Wahls et al. 1990a, 1991). The matrix contained $\sim 20 \mu \mathrm{g}$ of $M 26_{18}$ fragment per milliliter of settled Sepharose.

\section{Purification of M26 DNA-binding activity}

Unless stated otherwise centrifugations were for $15 \mathrm{~min}$ at $15,000 \mathrm{~g}$ at $0^{\circ} \mathrm{C}$. Column chromatography was at $4^{\circ} \mathrm{C}$. Column buffers were adjusted to $\mathrm{pH}$ at $4^{\circ} \mathrm{C}$, passed through $0.2-\mu \mathrm{m}$ filters, and degassed. All column buffers contained $50 \mathrm{mM}$ HEPES$\mathrm{NaOH}$ buffer, $10 \%$ glycerol, $0.2 \mathrm{~mm}$ EDTA, $0.1 \mathrm{~mm}$ phenylmethylsulfonyl flouride (PMSF), $1 \mathrm{~mm}$ dithiothreitol, and $\mathrm{NaCl}$ at a concentration designated by shorthand notation. For example, CB7.5/150 was column buffer at pH 7.5 containing $150 \mathrm{~mm}$ $\mathrm{NaCl}$. Unless indicated otherwise, buffers contained $1 \times$ protease inhibitors $11 \mu \mathrm{g} / \mathrm{ml}$ of aprotinin, $10 \mu \mathrm{g} / \mathrm{ml}$ of bestatin, 1 $\mu \mathrm{g} / \mathrm{ml}$ of leupeptin, $1 \mu \mathrm{g} / \mathrm{ml}$ of pepstatin, $20 \mu \mathrm{g} / \mathrm{ml}$ of $\mathrm{N}^{\alpha}-p-$ tosyl-L-lysine chloromethyl ketone-HCl). Fractions from the columns were assayed immediately for DNA-binding activity. A portion of each sample was adjusted to $50 \%$ glycerol, dispensed into aliquots, frozen in liquid $\mathrm{N}_{2}$, and stored at $-70^{\circ} \mathrm{C}$.

Frozen cells $(500 \mathrm{~g}$, frozen in $0.25 \mathrm{vol}$ of $\mathrm{CB} 7.9 / 500$ containing $20 \%$ glycerol, $1 \mathrm{mM}$ PMSF, and $4 \times$ inhibitors) were placed in a l-gallon Waring Blendor containing $\sim 500 \mathrm{ml}$ of liquid $\mathrm{N}_{2}$. The cells were opened by blending continuously for $30 \mathrm{~min}$ at $80 \%$ of full power (liquid $\mathrm{N}_{2}$ was added periodically to maintain a liquid slurry while blending). The powdered frozen lysate was thawed, adjusted to $500 \mathrm{~mm} \mathrm{NaCl}$ conductivity equivalents by addition of $5 \mathrm{M} \mathrm{NaCl}$, and centrifuged at $100,000 \mathrm{~g}$ for $30 \mathrm{~min}$, and the supernatant was collected. Nucleic acids were precipitated by stirring in $10 \%$ polyethyleneimine- $\mathrm{HCl}(\mathrm{pH} 7.5)$ to $0.05 \%$, incubating on ice for $15 \mathrm{~min}$, and centrifuging. This procedure yielded $12,700 \mathrm{mg}$ of fraction $\mathrm{I}(343 \mathrm{ml}$ at $37 \mathrm{mg} / \mathrm{ml}$ ).

Fraction I was brought to $41 \%$ of saturation with $\left(\mathrm{NH}_{4}\right)_{2} \mathrm{SO}_{4}$, incubated on ice for $15 \mathrm{~min}$, and centrifuged. The pellet was resuspended in $50 \mathrm{ml}$ of $\mathrm{CB} 7.25 / 150$, dialyzed to completion against $C B 7.25 / 150$, and clarified by centrifugation to yield $4800 \mathrm{mg}$ of fraction II $(80 \mathrm{ml}$ at $60 \mathrm{mg} / \mathrm{ml})$.

Fraction II was applied at $360 \mathrm{ml} / \mathrm{hr}$ to a $500 \mathrm{ml} \mathrm{SP}$-Sepharose (Pharmacia) column (5 cm diameter). The column was washed with $1500 \mathrm{ml} \mathrm{CB} 7.25 / 150$, and the bound proteins were eluted with a $2000 \mathrm{ml}$ gradient of $150-600 \mathrm{mM} \mathrm{NaCl}$ in CB7.25. Fractions containing M26 DNA binding activity eluted in a peak centered at $425 \mathrm{mM} \mathrm{NaCl}$. The active fractions were pooled, dialyzed to completion against CB7.25/200, and clarified by 
centrifugation to yield $226 \mathrm{mg}$ of fraction III $\mid 485 \mathrm{ml}$ at 465 $\mu \mathrm{g} / \mathrm{ml}$ ).

Fraction III was applied at $100 \mathrm{ml} / \mathrm{hr}$ to a $100-\mathrm{ml}$ ssDNAcellulose (U.S. Biochemical) column ( $2.5 \mathrm{~cm}$ diam.). The column was washed with $300 \mathrm{ml}$ of CB7.25/200, and the bound proteins were eluted with a $300-\mathrm{ml}$ gradient of $200-600 \mathrm{~mm}$ $\mathrm{NaCl}$ in $\mathrm{CB} 7.25$. Fractions containing $\mathrm{M} 26 \mathrm{DNA}$-binding activity eluted in a peak centered at $425 \mathrm{mM} \mathrm{NaCl}$. The active fractions were pooled, dialyzed to completion against CB7.25/200, and clarified by centrifugation to yield $32.9 \mathrm{mg}$ of fraction IV $(90$ $\mathrm{ml}$ at $365 \mu \mathrm{g} / \mathrm{ml})$.

Fraction IV was applied at $30 \mathrm{ml} / \mathrm{hr}$ to a $1-\mathrm{ml}$ Mono-S column (Pharmacia). The column was washed with $10 \mathrm{ml}$ of CB7.25/ 200 , and the bound proteins were eluted with a $60-\mathrm{ml}$ gradient of $200-600 \mathrm{~mm} \mathrm{NaCl}$ in CB7.25. The active fractions, which eluted in a peak centered at $340 \mathrm{mM} \mathrm{NaCl}$, were pooled, dialyzed to completion against CB $7.25 / 200$, and clarified by centrifugation to yield $9.75 \mathrm{mg}$ of fraction $\mathrm{V}(13 \mathrm{ml}$ at $750 \mu \mathrm{g} / \mathrm{ml})$.

Fraction $\mathrm{V}$ was mixed with $200 \mu \mathrm{g}$ of poly[d(I-C)]; incubated on ice for $10 \mathrm{~min}$, and applied at $15 \mathrm{ml} / \mathrm{hr}$ to an $8-\mathrm{ml} M 26_{18}$ DNA-Sepharose column (1 cm diam.). The column was washed with $60 \mathrm{ml}$ of CB7.25/200, and the bound proteins were eluted with an $80-\mathrm{ml}$ gradient of $200-600 \mathrm{~mm} \mathrm{NaCl}$ in $\mathrm{CB} 7.25$. Fractions containing M26 DNA-binding activity eluted in a peak centered at $425 \mathrm{~mm} \mathrm{NaCl}$. The active fractions were pooled to yield $10 \mu \mathrm{g}$ of fraction VI containing $\geqslant 50 \% \mathrm{Mts} 1$ and Mts 2 polypeptides by weight (judged by the intensity of bands on Coomassie-stained, SDS-polyacrylamide gels).

\section{Glutaraldehyde cross-linking of Mts1 and Mts2}

Aliquots $(500 \mu l)$ of protein fraction VI $/ \sim 250 \mathrm{ng}$ of protein) were mixed with $55-\mu \mathrm{l}$ aliquots of freshly diluted glutaraldehyde and incubated at $37^{\circ} \mathrm{C}$ for $10 \mathrm{~min}$. Samples were placed on ice, $65 \mu \mathrm{l}$ of $100 \%$ TCA was added, and the proteins were recovered by centrifugation for $30 \mathrm{~min}$ at $4^{\circ} \mathrm{C}$. The pellets were rinsed with $200 \mu \mathrm{l}$ of ice-cold acetone/ $1 \mathrm{mM} \mathrm{HCl}$ and spun for $5 \mathrm{~min}$, and the supernatant was discarded. The rinse was repeated a second time, and the pellets were then dried briefly, resuspended in SDS-PAGE loading buffer, heated, and fractionated on a $12 \%$ SDS-polyacrylamide gel (Laemmli 1970), which was stained with Coomassie.

\section{Reconstitution of binding activity from purified components}

Approximately $4 \mu \mathrm{g}$ of purified fraction VI was concentrated by TCA precipitation and fractionated on a $12 \%$ SDS-polyacrylamide gel, the Mts1 and Mts2 bands were excised, and the proteins were eluted in $500 \mu \mathrm{l}$ of dilution buffer [(DB) $50 \mathrm{~mm}$ HEPES at $\mathrm{pH} 7.25 ; 10 \%$ glycerol; $150 \mathrm{mM} \mathrm{NaCl} ; 100 \mu \mathrm{g} / \mathrm{ml}$ of BSA; $1 \mathrm{~mm} \mathrm{DTT]} \mathrm{containing} 0.1 \%$ SDS by rotating the tubes at $21^{\circ} \mathrm{C}$ for $15 \mathrm{hr}$. The eluted proteins were filtered (Millipore Millex-GV4 $0.22 \mu \mathrm{m}$ ), precipitated by the addition of acetone to $80 \%$ and centrifuged at $4{ }^{\circ} \mathrm{C}$ for $30 \mathrm{~min}$. The pellets were rinsed with $200 \mu$ of $80 \%$ acetone $/ 20 \% \mathrm{DB}$, dried briefly, resuspended in $45 \mu \mathrm{l}$ of $\mathrm{DB}$ containing $6 \mathrm{M}$ guanidine- $\mathrm{HCl}$, and incubated for $30 \mathrm{~min}$ at $21^{\circ} \mathrm{C}$. As a control, purified fraction VI was treated in an identical fashion (but without having been fractionated on SDS-polyacrylamide gel). The denatured proteins were mixed as indicated in Figure 6, diluted 50 -fold in DB, and allowed to renature for $6 \mathrm{hr}$ at $21^{\circ} \mathrm{C}$. The proteins were concentrated by filtration to $\sim 75 \mu \mathrm{l}$ (Millipore Centricon 10), and $5 \mu \mathrm{l}$ of each reaction was analyzed by the gel mobility retardation assay (Wahls et al. 1991) for the presence or absence of M26 DNAbinding activity.

\section{Acknowledgments}

We are grateful to Sue Amundsen, Patrick Dabert, Harvey Eisen, Steve Hahn, Steve Henikoff, Ywan Feng Li, Yukang Lin, Ron Reeder, Frank Stahl, Philippe Szankasi, and Andrew Taylor for critical reading of this manuscript. We thank Jürg Kohli for providing M13 clones of ade6-M26 bearing single base-pair substitutions. Computer analyses were made possible by a $\mathrm{Na}-$ tional Cancer Institute grant (NCI P30 CA15704-20) to the Fred Hutchinson Biocomputing Resource Center. This work was supported by a grant from the U.S. Public Health Service (GM 31693) to G.R.S., a National Institutes for Health training grant (5T32CA09437) to W.P.W., and a Damon Runyon-Walter Winchell postdoctoral fellowship (DRG-1110) to W.P.W.

The publication costs of this article were defrayed in part by payment of page charges. This article must therefore be hereby marked "advertisement" in accordance with 18 USC section 1734 solely to indicate this fact.

\section{References}

Alani, E., R. Padmore, and N. Kleckner. 1990. Analysis of wildtype and rad50 mutants of yeast suggest an intimate relationship between chromosome synapsis and recombination. Cell 61: 419-436.

Angel, T., B. Austin, and D.G. Catcheside. 1970. Regulation of recombination at the his-3 locus in Neurospora crassa. Aust. J. Biol. Sci. 23: 1129-1240.

Baldwin, A.S.J. 1988. Methylation interference assay for analysis of DNA-protein interactions. In Current Protocols in Molecular Biology, lst ed., vol. 2 (ed. F.M. Ausubel, R. Brent, R.E. Kingston, D.D. Moore, J.G, Seidman, J.A. Smith, and K. Struhl), pp. 12.3.1-12.3.6. John Wiley \& Sons/Greene, New York.

Bishop, D.K., D. Park, L. Xu, and N. Kleckner. 1992. DMCl: A meiosis-specific yeast homolog of $E$. coli recA required for recombination, synaptonemal complex formation, and cell cycle progression. Cell 69: 439-456.

Blackwood, E.M., L. Kretzner, and R.N. Eisenman. 1992. Myc and Max function as a nucleoprotein complex. Curr. Opin. Genet. \& Dev. 2: 227-235.

Cao, L., E. Alani, and N. Kleckner. 1990. A pathway for generation and processing of double-strand breaks during meiotic recombination in S. cerevisiae. Cell 61: 1089-1101.

DeVeaux, L.C., N.A. Hoagland, and G.R. Smith. 1992. Seventeen complementation groups of mutations decreasing meiotic recombination in Schizosaccharomyces pombe. Genetics 130: 251-262.

Fan, J.B., Y. Chikashige, C.L. Smith, O. Niwa, M. Yanagida, and C.R. Cantor. 1989. Construction of a NotI restriction map of the fission yeast Schizosaccharomyces pombe genome. $\mathrm{Nu}$ cleic Acids Res. 17: 2801-2818.

Greider, C.W. and E.H. Blackburn. 1987. The telomere terminal transferase of Tetrahymena is a ribonucleoprotein enzyme with two kinds of primer specificity. Cell 51: 887-898.

Grimm, C., J. Bähler, and J. Kohli. 1994. M26 recombinational hotspot and physical conversion tract analysis in the ade6 gene of Schizosaccharomyces pombe. Genetics 135: 41-51.

Gutz, H. 1971. Site specific induction of gene conversion in Schizosaccharomyces pombe. Genetics 69: 317-337.

Hawley, R.S. 1989. Exchange and chromosomal segregation in eucaryotes. In Genetic recombination (ed. R. Kucherlapati and G.R. Smith), pp 497-527. American Society for Microbiology, Washington, D.C.

Keil, R.L. and G.S. Roeder. 1984. Cis-acting, recombinationstimulating activity in a fragment of the ribosomal DNA of 
S. cerevisiae. Cell 39:377-386.

Kole, R. and S. Altman. 1981. Properties of purified ribonuclease P from Escherichia coli. Biochemistry 20: 1902-1906.

Laemmli, U.K. 1970. Cleavage of structural proteins during the assembly of the head of bacteriophage T4. Nature 227: 680685.

Lam, S.T., M.M. Stahl, K.D. McMilin, and F.W. Stahl. 1974. Rec-mediated recombinational hotspot activity in bacteriophage lambda. II. A mutation which causes hotspot activity. Genetics 77: 425-433.

Lin, Y. and G.R. Smith. 1994. Transient, meiosis-induced expression of the rec6 and rec12 genes of Schizosaccharomyces pombe. Genetics 136: 769-779.

Lin, Y., K.L. Larson, R. Dorer, and G.R. Smith. 1992. Meiotically induced rec7 and rec8 genes from Schizosaccharomyces pombe. Genetics 132: 75-85.

MacDonald, M.V. and H.L.K. Whitehouse. 1979. A buff spore colour mutant in Sordaria brevicollis showing high-frequency conversion. 1. Characterization of the mutant. Genet. Res. Camb. 34: 87-119.

Munz, P., K. Wolf, J. Kohli, and U. Leupold. 1989. Genetics overview. In Molecular biology of the fission yeast led. A. Nasim, P. Young, and B.F. Johnson), pp. 1-30. Academic Press, San Diego, CA.

Ponticelli, A.S. and G.R. Smith. 1989. Meiotic recombinationdeficient mutants of Schizosaccharomyces pombe. Genetics 123: $45-54$.

-1992. Context dependence of a eukaryotic recombination hotspot. Proc. Natl. Acad. Sci. 89: 227-231.

Ponticelli, A.S., E.P. Sena, and G.R. Smith. 1988. Genetic and physical analysis of the M26 recombination hotspot of Schizosaccharomyces pombe. Genetics 119: 491-497.

Resnick, M.A. 1976. The repair of double-strand breaks in DNA: A model involving recombination. I. Theor. Biol. 59: 97-106.

Sambrook, J., E.F. Fritsch, and T. Maniatis, 1989. Molecular cloning: A laboratory manual, 2nd ed. Cold Spring Harbor Laboratory Press, Cold Spring Harbor, New York.

Schuchert, P. and J. Kohli. 1988. The ade6-M26 mutation of Schizosaccharomyces pombe increases the frequency of crossing over. Genetics 119: 507-515.

Schuchert, P., M. Langsford, E. Käslin, and J. Kohli. 1991. A specific DNA sequence is required for high frequency of recombination in the ade6 gene of fission yeast. EMBO $I$. 10: $2157-2163$.

Stahl, F.W., J.M. Crasemann, and M.M. Stahl. 1975. Rec-mediated recombinational hot spot activity in bacteriophage lambda. III. Chi mutations are site-mutations stimulating Rec-mediated recombination. I. Mol. Biol. 94: 203-212.

Sun, H., D. Treco, N.P. Schultes, and J.W. Szostak. 1989. Double-strand breaks at an initiation site for meiotic gene conversion. Nature 338: 87-90.

Sun, H., D. Treco, and J.W. Szostak. 1991. Extensive 3'-overhanging, single-stranded DNA associated with the meiosisspecific double-strand breaks at the ARG4 recombination initiation site. Cell 64: 1156-1161.

Szankasi, P. and G.R. Smith. 1992. A DNA exonuclease induced during meiosis of Schizosaccharomyces pombe. I. Biol. Chem. 267: 3014-3023.

Szankasi, P., W.D. Heyer, P. Schuchert, and J. Kohli. 1988. DNA sequence analysis of the ade6 gene of Schizosaccharomyces pombe: Wild-type and mutant alleles including the recombination hotspot allele ade6-M26. I. Mol. Biol. 204: 917-925.

Szostak, J.W., T.L. Orr-Weaver, R.J. Rothstein, and F.W. Stahl. 1983. The double-strand-break repair model for recombination. Cell 33: 25-35.
Treco, D., and N. Arnheim. 1986. The evolutionarily conserved repetitive sequence $d(T G \cdot A C)_{n}$ promotes reciprocal exchange and generates unusual recombinant tetrads during yeast meiosis. Mol. Cell. Biol. 6: 3934-3947.

Voelkel-Meiman, K., R.L. Keil, and G.S. Roeder. 1987. Recombination-stimulating sequences in yeast ribosomal DNA correspond to sequences regulating transcription by RNA polymerase I. Cell 48: 1071-1079.

Wahls, W.P. 1994. RNA associated with a heterodimeric protein that activates a meiotic homologous recombination hotspot: RL/RT/PCR strategy for cloning any unknown RNA or DNA. PCR Methods Applic. 3: 272-277.

Wahls, W.P. and G.R. Smith. 1993. The M26 homologous recombination hotspot: Sequences, factors and chromosomal context. In Chromosomes today vol.11, ed. A.T. Sumner and A.C. Chandley|, pp. 351-363. Chapman \& Hall, London, $\mathrm{UK}$.

Wahls, W.P., L.J. Wallace, and P.D. Moore. 1990a. Hypervariable minisatellite DNA is a hotspot for homologous recombination in human cells. Cell 60: 95-103.

. 1990b. The Z-DNA motif $\mathrm{d}(\mathrm{TG})_{30}$ promotes reception of information during gene conversion events while stimulating homologous recombination in human cells in culture. Mol. Cell. Biol. 10: 785-793.

Wahls, W.P., G. Swenson, and P.D. Moore. 1991. Two hypervariable minisatellite DNA binding proteins. Nucleic Acids Res. 19: 3269-3274.

Wahls, W.P., J.M. Song, and G.R. Smith. 1993. Single-stranded DNA binding activity of $\mathrm{C}_{1}$-tetrahydrofolate synthase enzymes. I. Biol. Chem. 268: 23792-23798.

White, M.A., M. Wierdl, P. Detloff, and T.D. Petes. 1991. DNAbinding protein RAP1 stimulates meiotic recombination at the HIS4 locus in yeast. Proc. Natl. Acad. Sci. 88: 97559759.

White, M.A., M. Dominska, and T.D. Petes. 1993. Transcription factors are required for the meiotic recombination hotspot at the HIS4 locus in Saccharomyces cerevisiae. Proc. Natl. Acad. Sci. 90: 6621-6625.

Wu, T.-C. and M. Lichten. 1994. Meiosis-induced double-strand break sites determined by yeast chromatin structure. Science 263: $515-518$.

Young, L.S., H.M. Dunstan, P.R. Witte, T.P. Smith, S. Ottonello, and K.U. Sprague. 1991. A class III transcription factor composed of RNA. Science 252: 542-546. 


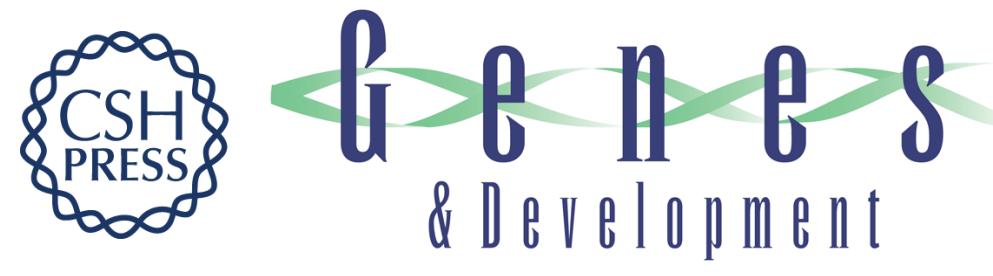

\section{A heteromeric protein that binds to a meiotic homologous recombination hot spot: correlation of binding and hot spot activity.}

W P Wahls and G R Smith

Genes Dev. 1994, 8:

Access the most recent version at doi:10.1101/gad.8.14.1693

References This article cites 40 articles, 17 of which can be accessed free at:

http://genesdev.cshlp.org/content/8/14/1693.full.html\#ref-list-1

License

Email Alerting

Service

Receive free email alerts when new articles cite this article - sign up in the box at the top right corner of the article or click here.

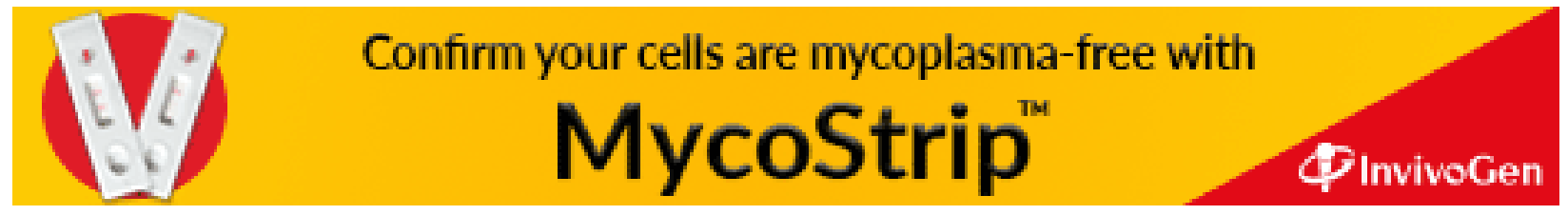

